\title{
Wood Energy in Developed Economies \\ Resource Management, Economics and Policy
}

Francisco X. Aguilar (ed.), 2014. ISBN 978-0415711692 Routledge, New York,

NY. US \$130 + shipping. Contact: www.routledge.com/books/details/9780415711692/

$\mathbf{T}_{\mathrm{i}}^{\mathrm{h}}$ here has been a recent resurgence of interest in wood energy as part of a sustainable range of renewable energy options. This book addresses the current gap in the energy and public policy literature for a reference book that compiles the most-recent wood energy assessments, and evaluates current and potential future wood energy uses and the role for public policy to foster efficient use of the most-widely consumed renewable energy in the world.

It brings together a group of expert authors covering topics from forest management, operations and engineering, to socio-economics and energy policy perspectives. It thus covers practical

issues such as silviculture, harvesting, processing, comparative cost estimates, public policy tools and market effects. As such the book provides a comprehensive review of the complex dimensions of wood energy as well as practical guidance for professionals, researchers and advanced students. It will also provide invaluable guidance for economic development agencies, practitioners and policy-makers, when evaluating the impacts of wider wood energy adoption as part of a strategy for sustainable energy generation. The main focus is on industrialised production and developed economies, particularly the USA and Europe.

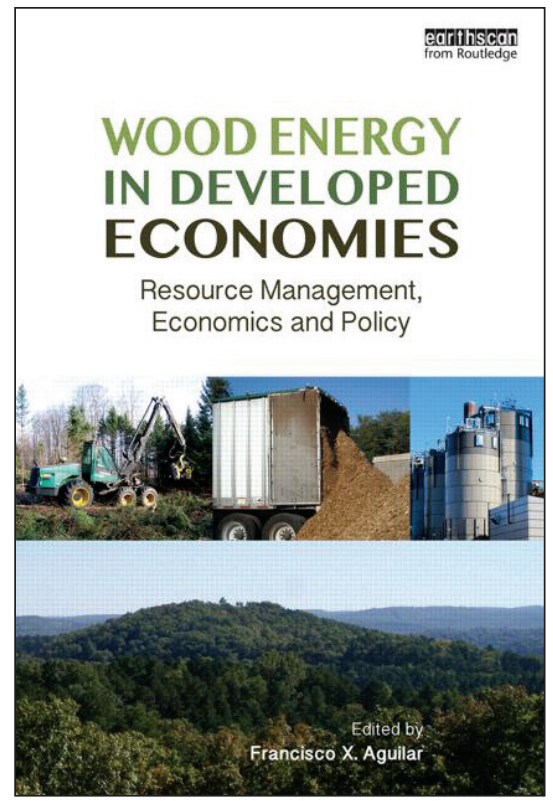

BOOK REUIEWS \& REVUE DE LIURES

Constitutions and the Commons The Impact of Federal Governance on Local, National, and Global Resource Management

Blake Hudson. 2014. ISBN 978-1-61726-096-4 RFF Press, New York. 277 pages.

USD $\$ 74.03+$ shipping

ince its publication in 1968, Garrett $\checkmark$ Hardin's 'The Tragedy of the Commons' has been cited thousands of times. The article has become so influential that a new discipline of scholarship known as 'the Commons Analysis' has come into existence. The woes of the commons are well understood. Without an effective control mechanism being put in place, herders have an incentive to appropriate open access grassland by continually increasing the size of their individual herd. This behavior results in overgrazing and, in turn, severe degradation of the resource base. Scholars have suggested an array of remedies to the tragic outcomes of the commons appropriation. Privatization and government regulation are two ends of the spectrum of possible solutions. However, neither of the two would guarantee the elimination of the commons problems, and Blake Hudson uses this volume to explain, in particular, why federal systems of government permit the persistence of commons appropriation.

Strictly speaking, the Hardinian type of unrestricted open access does not exist anymore. In reality, natural resources around the world are subject to a varying degree of institutional control. The context that Professor Hudson has established at the outset of this book is one where natural capital is embedded within a web of government systems characterized by a federal nation's constitutional structure. Three most important pieces are explained in Part I, namely: (i) the definition, nature and scope of the commons problem; (ii) natural capital and why it is prone to

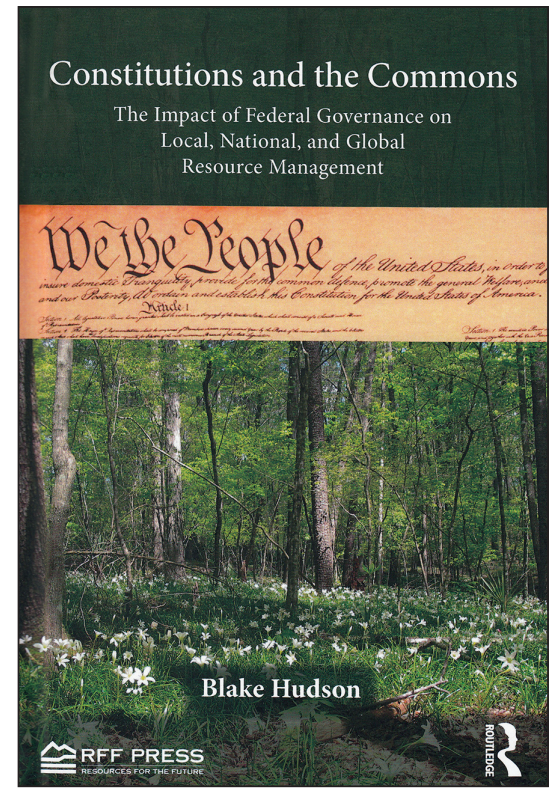

appropriation; and, (iii) the federal system, and the prominent role of a nation's constitution and its effects on natural resource governance at subnational, national and international levels. The first two chapters provide a 
theoretical framework for the remainder of the volume.

Part II is concerned with decentralization of the commons, using the U.S. federal system as an illustration of nested commons. Part III focuses on the federalization of the commons, again citing a number of U.S. examples. After introducing the role of constitutions in establishing the legal framework for managing the natural environment, the author describes a continuum of constitutionally driven natural resource management scenarios, from local to national, and then to global governance. In spite of its many advantages, a federal system suffers from the nesting of different levels of government, often resulting in a legal entrenchment at multiple scales. In consequence, legal deficiencies in a federal constitutional structure can lead to nested commons tragedies. The author shows that national governments in federal systems are at the centre of a constitutional "nested governance commons," with lower levels of government potentially acting as rational herders on the national commons and national governments likely behaving like Hardinian herders on the global commons. In Part IV, the author takes the reader to the international level where he explains how a federal system may lead to the tragedy of the commons at the global level.

This book brings into focus an important but little examined issue of how the constitution of a federal nation can help or hinder the ability of the national government to ensure proper management of the country's domestic natural resources. Furthermore, the chapters ponder over the extent to which the constitution is capable of aligning sub-national-level authorities to satisfy the terms of international environmental treaties. Professor Hudson argues that national governments in federal systems are crucial to establishing sustainable management of resources across scales. While the main focus is on the U.S., there is substantive coverage of several nations including Canada, Australia and Brazil.

The book concludes by discussing how federal systems may be strengthened, in the absence of adequate national constitutional authority over natural resources. Hudson proposes a kind of federalism where constitutions facilitate robust nationwide inputs into natural resources management, preferably by adopting national minimum standards, with buy in from subnational governments. The author argues in favor of the fortification of keystone constitutions to facilitate more effective natural resource governance through rebalancing regulatory authority between central and lower-level governments. In Hudson's view, although constitutional constraints limit a federal government's regulatory intervention in sub-national resource management regimes, effective resource management within federal systems can still be enhanced when collaborative efforts are fostered across scales.
This volume is a valuable read for natural resource professionals including foresters, livestock specialists, economists, political scientists, as well as policy analysts. In particular, law school students and graduate students in resource economics will benefit from the unique methodological approach that the author has employed in deconstructing the nested commons problems at multiple scales. The biggest contribution of this well researched book is the author's identification of the governance construct of a federal system itself being prone to taking on the commons attributes with perverse effects. Recognizing the enormous challenges and complexities in tackling the commons problems along the spectrum from decentralized private ownership to centralized state ownership, and the accompanying strengths and limitations, is an important step towards the fortification of keystone constitutions.

Lastly, it is worth noting that RFF Press maintains a high standard in terms of the fine quality of the books that it publishes. In the Internet era, having an exquisitely produced volume such as this one standing on the bookshelf will serve as a reminder that the need to examine the role of constitutions in addressing the commons problems will persist in the years to come. Reviewed by Dr. Sen Wang
Atlantic Forestry Centre
Fredericton, Canada 


\section{Multiaged Silviculture Managing for Complex Forest Stand Structures}

Kevin L. O'Hara. 2014. ISBN 978-0-19-870307-5 Oxford University Press, Oxford, U.K. CA $\$ 54.13+$ shipping. 213pages, softcover.

The perpetual forest stands promised by multiaged silviculture make the concept of this management system easy to love, but understanding and commitment are needed for its implementation. Multiaged Silviculture: Managing for Complex Forest Stand Structures by Dr. Kevin O'Hara does a good job of supplying much of the needed understanding. To the best of my knowledge, this is the first book that deals exclusively with multiaged silviculture in a comprehensive and global manner, making it particularly valuable reference.

Dr. O'Hara is a professor of silviculture at the University of CaliforniaBerkeley, and has carried out a substantial amount of silvicultural research, primarily in the western United States, but also in Europe. For a number of years, he was the Co-ordinator of the International Union of Forest Research Organizations Uneven-aged Silviculture Research Group.

Terminology, which can become a quagmire in discussions of silviculture, is confronted within the first few pages of the book. "Uneven-aged silviculture" is a traditional term, but "multiaged silviculture" is broader, and also includes emerging systems that promote variation in spatial patterns and size structure. The treatment of terminology throughout the book is for the most part clear and is effective in avoiding termi- nological quicksand. It is curious, however, that the book's subtitle, "Managing for Complex Forest Structures", can apply to even-aged species mixtures.

Successful multiaged silviculture must be carried out within the boundaries imposed by stand dynamics. Accordingly, several of the initial book chapters are devoted to the dynamics of disturbances, forest gaps and multiaged stands. Subsequent chapters deal with aspects of multiaged management systems ranging from regeneration and tending to growth projection and genetics. Discussions of all topics are supported by extensive and up-to-date references to research carried out mainly in temperate forests of the world. Because the book emphasizes the scientific foundations of multiaged silviculture, it fulfills its stated objectives of serving as a text for advanced silviculture courses and as a reference book for scientists.

The book is perhaps somewhat less successful in serving as a reference for managers. The book provides many interesting examples of multiaged silviculture from around the world (e.g., southern pines in the U.S., boreal conifers in Finland and southern beech in New Zealand), but many of these examples have not been implemented outside of research trials. The book includes a chapter on the history of multiaged silviculture, but gives little

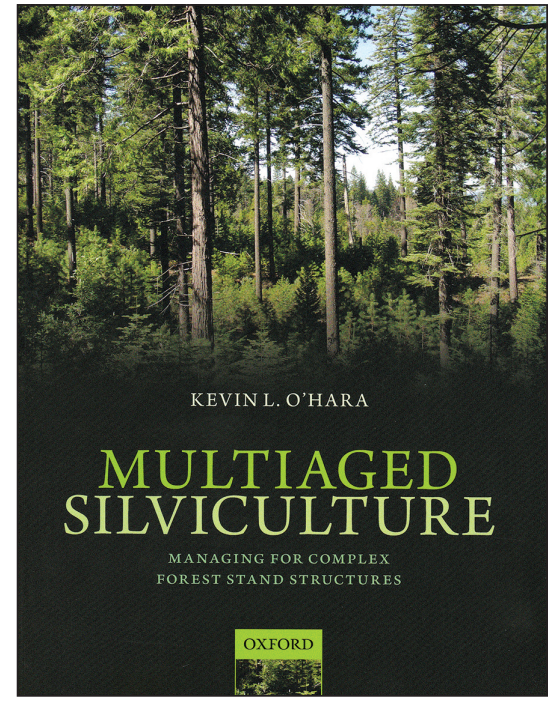

sense of how widely this system is actually practiced in different areas. The factors that have led to what is likely the world's greatest concentration of operational multiaged silviculture in the tolerant hardwood forests of eastern North America are not examined.

Overall, the book makes a strong case that diversification of silvicultural practices is needed to respond to the multiple objectives and issues that face forest management today. Diversification is needed to maintain biodiversity, to build resistance and resilience in the face of a changing climate, to meet social demands and to broaden economic opportunities. It is therefore troubling that the burst of activity towards silvicultural diversification across Canada during the 1990s has now largely waned.

Reviewed by Art Groot 